\title{
Formation of Whiskers and Hillocks on the Surface of Sn-6.6RE Alloys
}

\author{
T.H. CHUANG, C.C. CHI, and H.J. LIN
}

\begin{abstract}
As-cast $\mathrm{Sn}-6.6 \mathrm{Ce}, \mathrm{Sn}-6.6 \mathrm{Lu}$, and $\mathrm{Sn}-6.6 \mathrm{La}$ alloys contain peritectic structures of near $\beta$-Sn matrix embedded with $\mathrm{CeSn}_{3}, \mathrm{Lu}_{4} \mathrm{Sn}_{5}$, and $\mathrm{LaSn}_{3}$ clusters, respectively, among which those of $\mathrm{LaSn}_{3}$ are the smallest in size. After air storage at room temperature, Sn-6.6Ce and Sn-6.6Lu reveal a much higher tendency than Sn-6.6La to form long threadlike whiskers on the surface of $\mathrm{CeSn}_{3}$ phase. Sn-6.6La shows the earlier appearance of coarse hillocks during storage at $150{ }^{\circ} \mathrm{C}$ in comparison to the $\mathrm{Sn}-6.6 \mathrm{Ce}$ and $\mathrm{Sn}-6.6 \mathrm{Lu}$, but these hillocks cease to grow after a short duration. In contrast, the hillocks in $\mathrm{Sn}-6.6 \mathrm{Ce}$ and $\mathrm{Sn}-6.6 \mathrm{Lu}$ can grow to large sizes. This discrepancy correlates to the lower oxidation rate of $\mathrm{LaSn}_{3}$ intermetallic phase than those of $\mathrm{CeSn}_{3}$ and $\mathrm{Lu}_{4} \mathrm{Sn}_{5}$, which is attributed to the higher chemical activity of La as compared to Ce and $\mathrm{Lu}$. In addition, the smaller size of the $\mathrm{LaSn}_{3}$ clusters also leads to the lower amount of tin atoms released and lower compressive stress accumulated after oxidation, which result in the slower whisker and hillock growth in Sn-6.6La alloy as compared to those in $\mathrm{Sn}-6.6 \mathrm{Ce}$ and $\mathrm{Sn}-6.6 \mathrm{Lu}$.
\end{abstract}

DOI: $10.1007 / \mathrm{s} 11661-007-9426-9$

(C) The Minerals, Metals \& Materials Society and ASM International 2008

\section{INTRODUCTION}

THE addition of rare-earth (RE) elements into solders has been reported to have beneficial effects for their wettability ${ }^{[1]}$ tensile strength, ${ }^{[2]}$ creep resistance, ${ }^{[2,3]}$ and ductility. ${ }^{[4]}$ Such an alloying design has been considered a promising method for the development of $\mathrm{Pb}$-free solders. ${ }^{[4]}$ However, we found by accident that amazingly rapid growth of tin whiskers occurred on the surface of Ce-doped $\mathrm{Sn} 3 \mathrm{Ag} 0.5 \mathrm{Cu}$ solders. ${ }^{[5-7]}$ It is known that whisker formation can cause short circuits in solder joints and is risky for the reliability of electronic devices in applications. ${ }^{[8]}$ According to our observations, ${ }^{[5-7]}$ fiber-shape whiskers grow to a length of more than $100 \mu \mathrm{m}$ after storage at room temperature for 10 days in these alloys. If they are heated at $150^{\circ} \mathrm{C}$, coarse hillocks appear in as soon as 30 minutes. It has also been shown that such abnormal whisker and hillock growth is attributed to the predominant oxidation of RE-containing intermetallic phase formed in the matrix of these solder alloys. In order to further confirm this mechanism, binary tin alloys with various RE elements such as La, $\mathrm{Ce}$, and $\mathrm{Lu}$ added were investigated. It is known that the electron configurations of $\mathrm{La}^{57}, \mathrm{Ce}^{58}$, and $\mathrm{Lu}^{71}$ atoms are $4 \mathrm{f}^{0} 5 \mathrm{~d}^{1} 6 \mathrm{~s}^{2}, 4 \mathrm{f}^{1} 5 \mathrm{~d}^{1} 6 \mathrm{~s}^{2}$, and $4 \mathrm{f}^{14} 5 \mathrm{~d}^{1} 6 \mathrm{~s}^{2}$, respectively. The chemical activities of these RE elements have the tendency of $\mathrm{La}>\mathrm{Ce}>\mathrm{Lu}$, which can influence their intermetallic phases and oxidation reactions. This study focused on the morphology and growth of whiskers and hillocks on the surface of these Sn-6.6RE alloys and the

T.H. CHUANG, Professor, C.C. CHI, Doctoral Candidate, and H.J. LIN, Doctoral Candidate, are with the Institute of Materials Science and Engineering, National Taiwan University, Taipei 106,

Taiwan R.O.C. Contact e-mail: tunghan@ntu.edu.tw

Manuscript submitted June 15, 2007.

Article published online January 26, 2008 correlation with the chemical activity and oxidation behavior of various RE elements. In addition, the volume expansion of oxide layers on the RE-containing intermetallics leads to a compressive stress that extrudes the tin atoms out to form the whiskers and hillocks. The size of these intermetallic phases should affect the behavior of whisker and hillock growth, a factor which will also be considered in this study.

\section{EXPERIMENTAL}

For the preparation of various Sn-6.6 wt pct RE alloys, pure Sn (99.9 pct) and pure RE elements (Ce, Lu, and La) were melted at $1000^{\circ} \mathrm{C}$ under a $10^{-4} \mathrm{~Pa}$ vacuum. After solidification, the ingots were cut with a diamond saw. The surfaces of the specimens were ground with 2000-grit $\mathrm{SiC}$ paper and polished with $0.3-\mu \mathrm{m} \mathrm{Al}_{2} \mathrm{O}_{3}$ powder. After storage at room temperature and $150{ }^{\circ} \mathrm{C}$ for various time periods, the morphology of the tin whiskers was observed by scanning electron microscopy (SEM). The chemical composition of the intermetallic phase formed in the alloy matrix was analyzed via an electron probe microanalyzer (EPMA). For the study of the oxidation behaviors of these alloys, the weight gain percentage $\left(\frac{\text { weight gain }}{\text { original weight }} \times 100 \mathrm{pct}\right)$ of the specimens was continuously measured at $150^{\circ} \mathrm{C}$ in an air furnace using a thermal gravity analyzer (TGA). In addition, the weight gain percentage of the specimens during storage in air at room temperature was also measured intermittently with a microbalance.

\section{RESULTS AND DISCUSSION}

The microstructures of the various Sn-6.6RE alloys after casting are shown in Figure 1. It can be seen in 

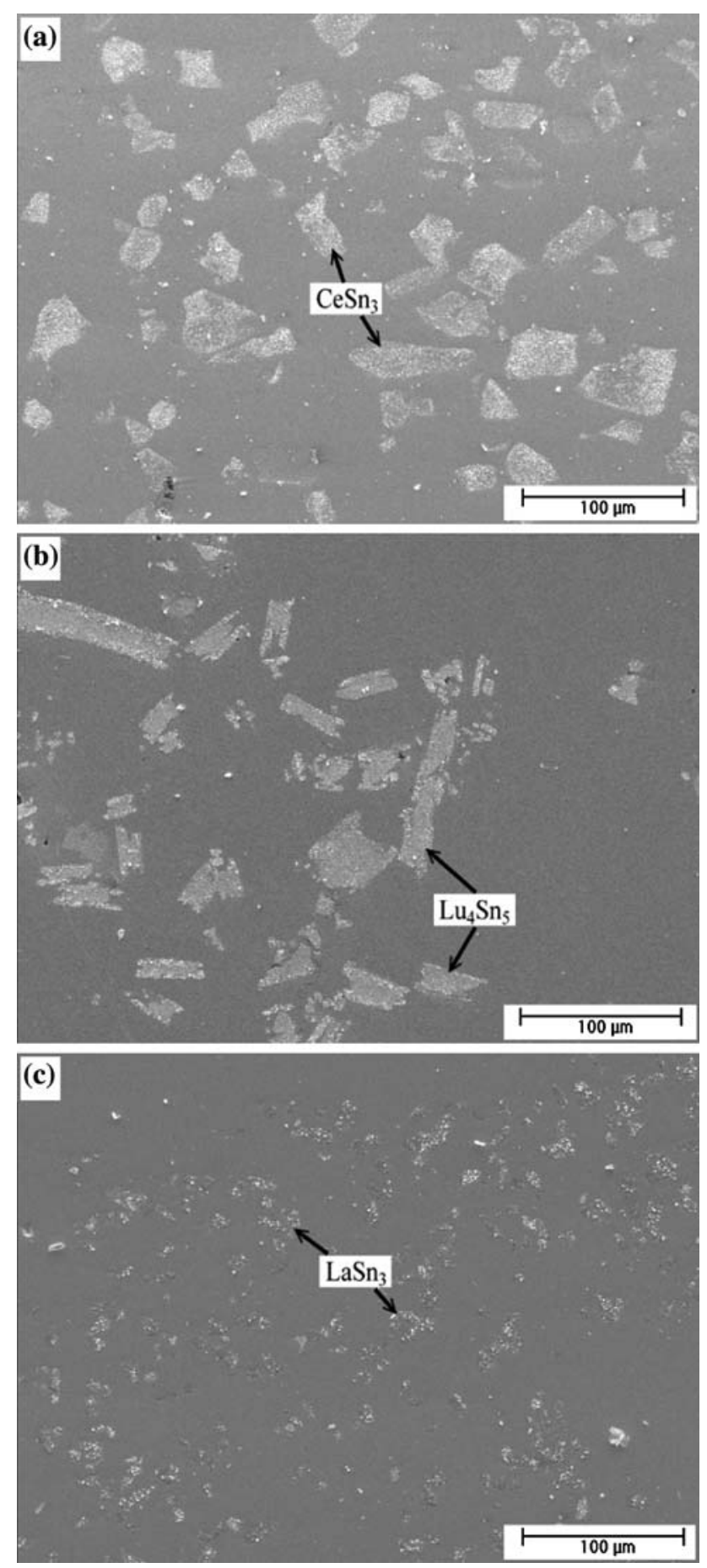

Fig. 1-Microstructure of the as-cast RE element-doped solders: $(a)$ Sn-6.6Ce, (b) Sn-6.6Lu, and (c) Sn-6.6La.

Figure 1(a) that clusters with an average size of $32 \mu \mathrm{m}$ appear in the matrix of the Sn-6.6Ce alloy. The EMPA analysis indicates that the composition (at. pct) of the clusters is $\mathrm{Ce}: \mathrm{Sn}=24.4: 75.6$, which corresponds to the $\mathrm{CeSn}_{3}$ intermetallic compound. According to the binary $\mathrm{Ce}-\mathrm{Sn}$ phase diagram, these $\mathrm{CeSn}_{3}$ clusters result from a peritectic reaction during solidification of $\mathrm{Sn}-6.6 \mathrm{Ce}$ alloy. ${ }^{[9]}$ The matrix of alloy should consist of $\beta$-Sn mixed with a small amount of eutectic $\mathrm{CeSn}_{3}$ phase. In
Figure 1(b), columns with a length of about $45 \mu \mathrm{m}$ can be observed in the Sn-6.6Lu specimen. These peritectic columns have a composition (at. pct) of $\mathrm{Lu}: \mathrm{Sn}=$ 44.4:55.6, which is analyzed as $\mathrm{Lu}_{4} \mathrm{Sn}_{5}$ phase. In contrast to the Sn-6.6Ce and Sn-6.6Lu alloys, Figure 1(c) reveals that many fine particles with an average size of $7 \mu \mathrm{m}$ have appeared in the matrix of Sn-6.6La during the solidification process. The composition (at. pct) of these fine peritectic particles as analyzed is $\mathrm{La}: \mathrm{Sn}=25.8: 74.2$, which corresponds to the $\mathrm{LaSn}_{3}$ phase in the binary La-Sn phase diagram. ${ }^{[10]}$ It is known that the chemical activity of La is higher than those of $\mathrm{Ce}$ and $\mathrm{Lu}$. This strong activity of $\mathrm{La}$ causes its predominant reaction with $\mathrm{Sn}$ atoms. It results in a much higher nucleation rate for the peritectic reaction of $\mathrm{LaSn}_{3}$ phase as compared to the $\mathrm{CeSn}_{3}$ and $\mathrm{Lu}_{4} \mathrm{Sn}_{5}$ phases, which leads to the formation of fine dispersed $\mathrm{LaSn}_{3}$ particles in the Sn-6.6La matrix.

After air storage at room temperature for 30 minutes, the surfaces in the regions of the RE-containing intermetallics in the Sn-6.6Ce, Sn-6.6Lu, and Sn-6.6La alloys are covered with many bright particles of consistent size, about $0.8 \mu \mathrm{m}$, as shown in Figure 2. The chemical composition of these fine particles is pure tin, which is considered to be the initial sprouts of the tin whiskers. The result indicates that the incubation times for the appearance of tin whiskers at room temperature are similar for all Sn-6.6RE alloys in this study. However, further increasing the storage time in air caused the formation of many long threadlike whiskers on the $\mathrm{CeSn}_{3}$ and $\mathrm{Lu}_{4} \mathrm{Sn}_{5}$ intermetallics phases, as revealed in Figures 3(a) and (b). In comparison to the rapid lengthening of whiskers in $\mathrm{Sn}-6.6 \mathrm{Ce}$ and $\mathrm{Sn}-6.6 \mathrm{Lu}$, Figure 3(c) indicates that the tin sprouts on the surface of $\mathrm{LaSn}_{3}$ intermetallics grew only slightly.

In order to confirm the differences in whisker growth tendencies in various $\mathrm{Sn}-6.6 \mathrm{RE}$ solders, the specimens were heated at $150{ }^{\circ} \mathrm{C}$ in an air furnace for 60 minutes. Figure 4 reveals that coarse hillocks appeared around the $\mathrm{LaSn}_{3}$ intermetallics, while the surfaces of $\mathrm{CeSn}_{3}$ and $\mathrm{Lu}_{4} \mathrm{Sn}_{5}$ phases contain small tin particles similar to the initial whisker sprouts observed in Figures 2(a) and (b). It can also be seen in Figure 4(c) that the formation of hillocks in this case prevented other tin particles from sprouting from the interior region of the $\mathrm{LaSn}_{3}$ phase. Although the coarse hillocks appeared quite early in the Sn-6.6La alloy, they grew very slowly with an increase of the storage time to 224 hours at $150{ }^{\circ} \mathrm{C}$, as evidenced in Figure 5(c). In contrast, Figures 5(a) and (b) show that in the Sn-6.6Ce and Sn-6.6Lu, respectively, the hillocks grew rapidly to a large size after 224 hours storage at $150{ }^{\circ} \mathrm{C}$.

In comparison to the morphology of RE-containing intermetallics observed on the surface of Sn-6.6RE alloys after air storage, both tin whiskers and hillocks were absent when specimens were aged at room temperature for 480 hours under $10^{-2} \mathrm{~Pa}$ vacuum, as illustrated in Figures 6(a) through (c). Similar morphology can be observed in the specimens stored at $150{ }^{\circ} \mathrm{C}$ under $10^{-2} \mathrm{~Pa}$ vacuum for 2 hours (Figure 7). The results indicate that the growth of tin whiskers and hillocks is attributed to the predominant oxidation of 

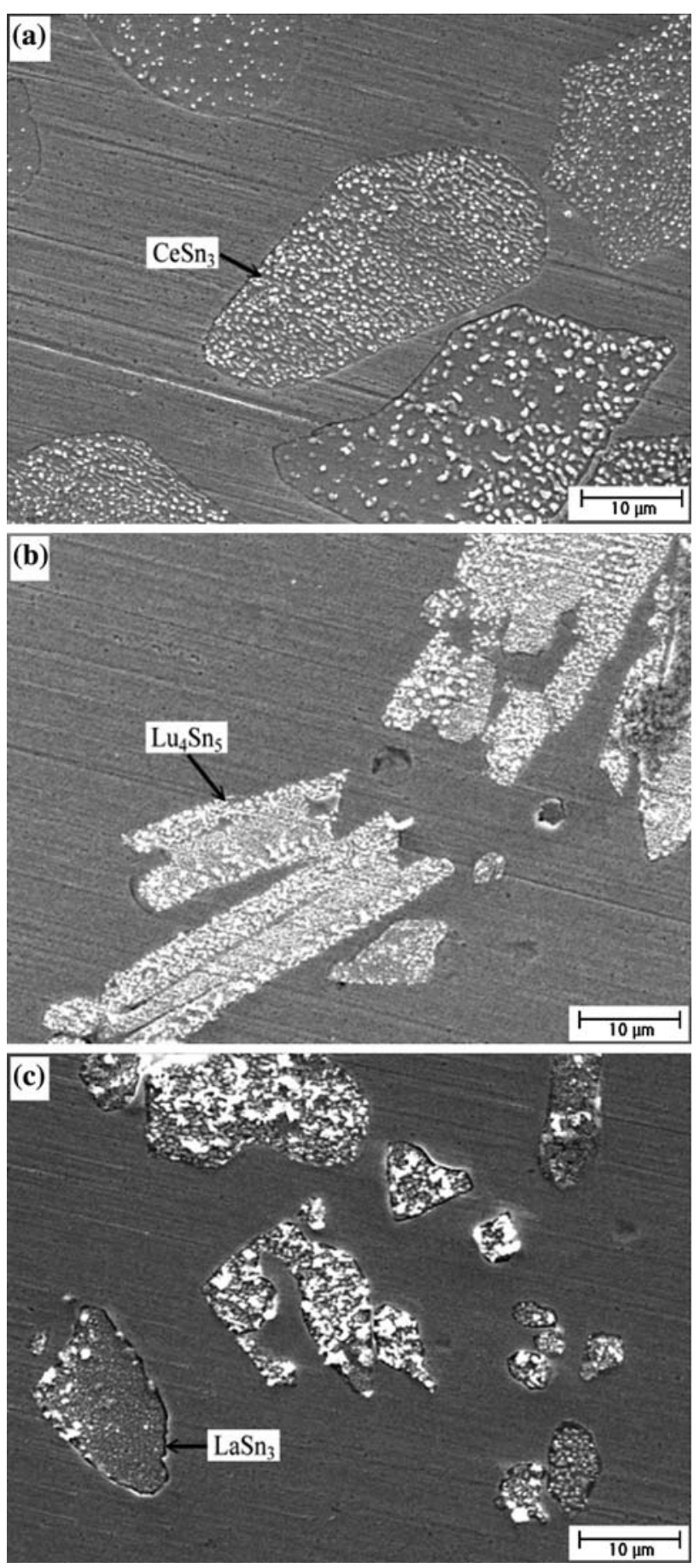

Fig. 2-Morphology of RE-containing intermetallic phases in various solders distributed with tin sprouts after air storage at room temperature for $30 \mathrm{~min}$ : (a) Sn-6.6Ce, (b) $\mathrm{Sn}-6.6 \mathrm{Lu}$, and (c) Sn-6.6La.

RE-containing intermetallics with oxygen. This inference can be confirmed by the EPMA analyses of the outer surface of RE-containing intermetallics during air storage at room temperature and $150{ }^{\circ} \mathrm{C}$ for various times. Figures 8(a) through (c) show that the oxygen contents (at. pct) on the surface of RE-containing intermetallics in Sn-6.6Ce, Sn-6.6Lu, and Sn-6.6La specimens stored at room temperature in air for
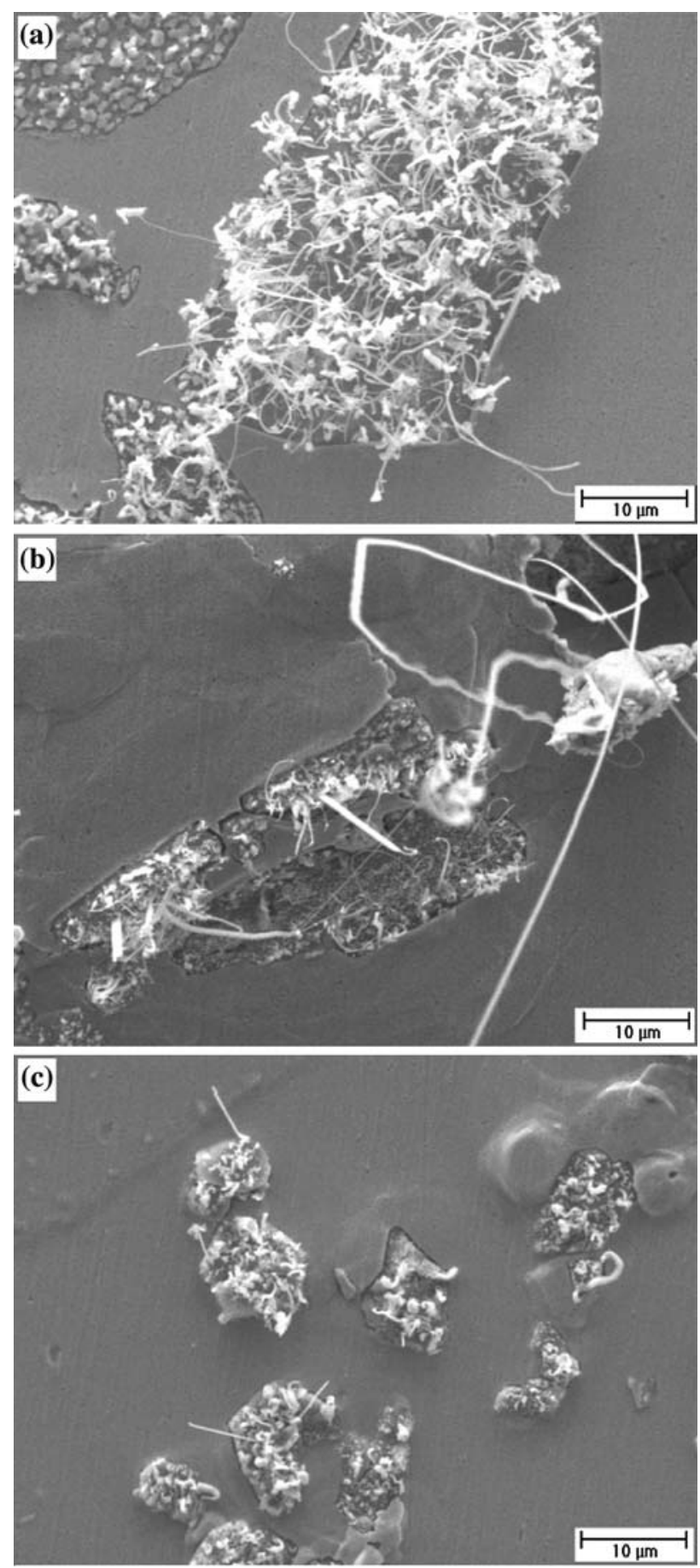

Fig. 3-Threadlike tin whiskers on the surface of RE-containing intermetallic phases in various solders after air storage at room temperature for $559 \mathrm{~h}:(a) \mathrm{Sn}-6.6 \mathrm{Ce},(b) \mathrm{Sn}-6.6 \mathrm{Lu}$, and (c) Sn-6.6La.

150 hours increase drastically from $13.8,14.5$, and 11.5 to $49.9,50.4$, and 45.2 , respectively. In contrast, the tin contents on the surface of $\mathrm{CeSn}_{3}, \mathrm{Lu}_{4} \mathrm{Sn}_{5}$, and $\mathrm{LaSn}_{3}$ drop to $20.5,29.1$, and 35.7 , respectively, while the concentrations of $\mathrm{RE}$ elements $(\mathrm{Ce}, \mathrm{Lu}$, and $\mathrm{La})$ remain almost constant. Similar results are shown in Figures 9(a) through (c) for the Sn-6.6RE specimens during $150{ }^{\circ} \mathrm{C}$ storage in an air furnace. In this case, the oxygen 

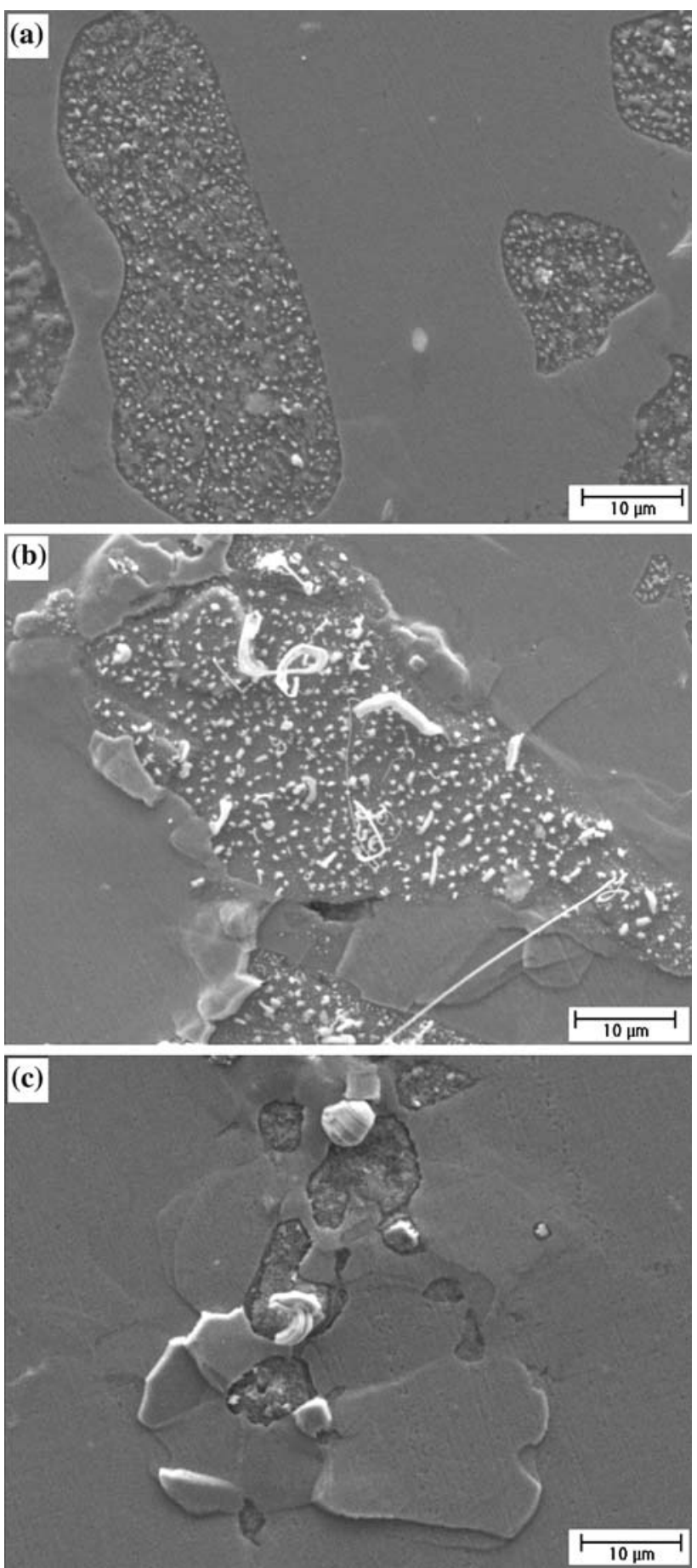

Fig. 4-Hillock-type whiskers on the surface of RE-containing intermetallic phases in various solders after air storage at $150{ }^{\circ} \mathrm{C}$ for 60 min: (a) Sn-6.6Ce, (b) Sn-6.6Lu, and (c) Sn-6.6La.

contents (at. pct) increase from 14.8, 22.9, and 18.6 to 53.8, 40.1, and 48.8 for $\mathrm{Sn}-6.6 \mathrm{Ce}, \mathrm{Sn} 6.6 \mathrm{Lu}$ and $\mathrm{Sn}-6.6 \mathrm{La}$ alloys, respectively. Corresponding to the increase in oxygen contents, the concentrations of RE elements (Ce, $\mathrm{Lu}$, and $\mathrm{La}$ ) on the surfaces of $\mathrm{CeSn}_{3}, \mathrm{Lu}_{4} \mathrm{Sn}_{5}$, and $\mathrm{LaSn}_{3}$ phases also rise to $33.3,48.5$, and 19.5 , respectively, while the tin contents decrease to $12.9,11.5$, and 31.7. The results provide evidence that the outer surfaces
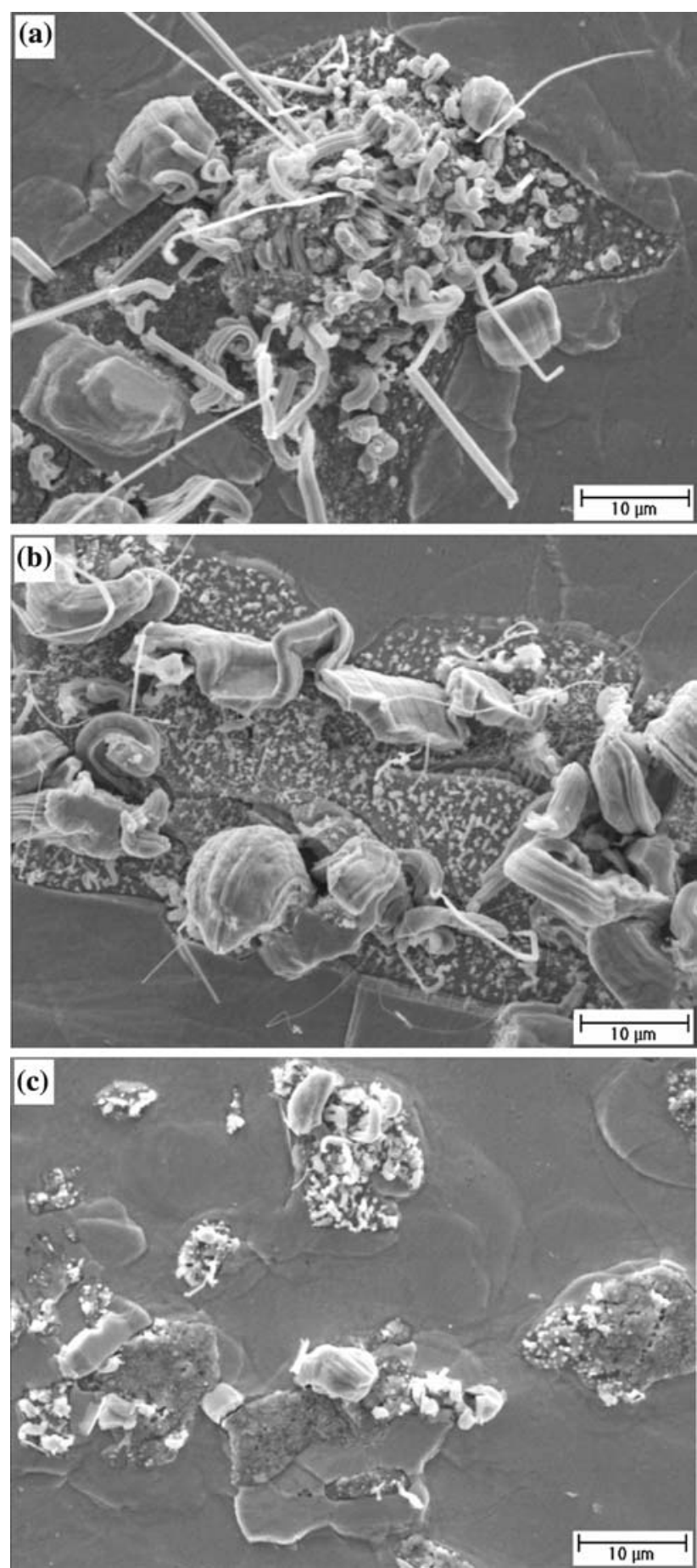

Fig. 5-Hillock-type whiskers on the surface of RE-containing intermetallic phases in various solders after air storage at $150{ }^{\circ} \mathrm{C}$ for 224 h: (a) Sn-6.6Ce, (b) Sn-6.6Lu, and (c) Sn-6.6La.

of RE-containing intermetallic phases in the Sn-6.6Ce, $\mathrm{Sn}-6.6 \mathrm{Lu}$, and $\mathrm{Sn}-6.6 \mathrm{La}$ alloys have oxidized to form RE oxides and pure tin due to the higher chemical activity of $\mathrm{RE}$ elements than that of tin. The tin atoms released from the oxidation reaction are considered to be the source of the formation of tin sprouts and threadlike whiskers. For the driving force of whisker growth, the diffusion of oxygen atoms into the RE-containing 

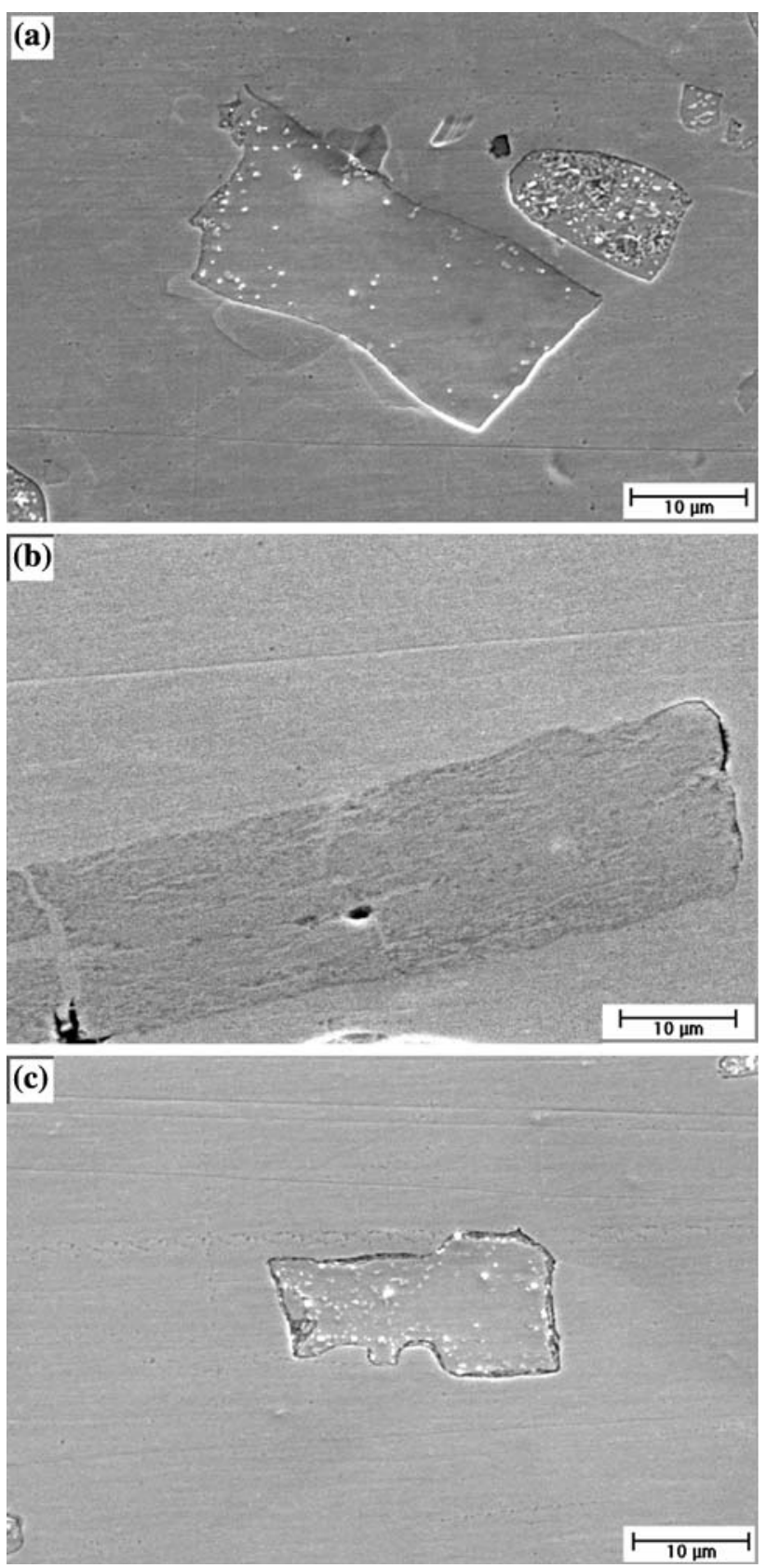

Fig. 6-Morphology of RE-containing intermetallic phases in Sn-6.6RE alloys after storage in a vacuum furnace of $10^{-2} \mathrm{~Pa}$ at room temperature for $480 \mathrm{~h}$ : (a) Sn-6.6Ce, (b) Sn-6.6Lu, and (c) Sn-6.6La.

intermetallics creates compressive stress that extrudes these resultant tin atoms out of the RE oxide layer. Additional compressive stress originating from the invasion of oxygen through the interface between RE intermetallics and the alloy matrix causes the tin atoms released after oxidation to combine with a certain amount of Sn-6.6RE matrix around the RE intermetallic clusters to form the coarse hillocks, which are extruded out of the RE intermetallics/alloy matrix interfaces.

In order to further confirm the growth mechanism of tin whiskers on the surface of Sn-6.6RE alloys, specimens were cut across the RE-containing intermetallics.
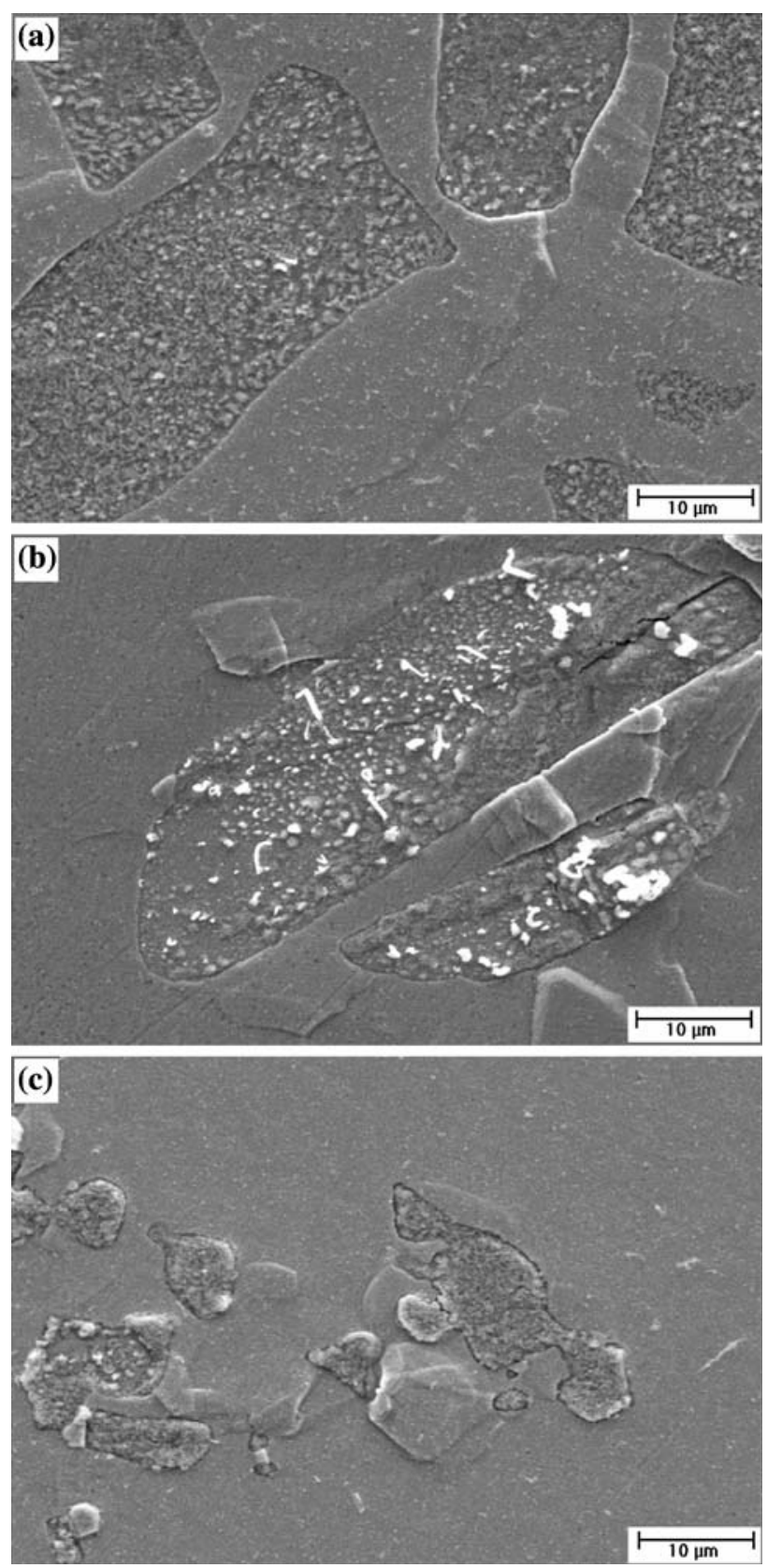

Fig. 7-Morphology of RE-containing intermetallic phases in Sn-6.6RE alloys after storage in a vacuum furnace of $10^{-2} \mathrm{~Pa}$ at $150{ }^{\circ} \mathrm{C}$ for $2 \mathrm{~h}$ : (a) Sn-6.6Ce, (b) Sn-6.6Lu, and (c) Sn-6.6La.

It can be seen in Figure 10 that oxide layers appear on the outer surface of the RE intermetallic phase in Sn6.6RE specimens stored at room temperature for 48 hours. Pure tin atoms released by the RE intermetallics after the oxidation reaction are also found to be inserted in the oxides with a lamellar structure (bright in color) parallel to the specimen surface. In addition, cracks can be observed in the oxide layers. It is believed that the tin atoms accumulated in the pure tin lamellae penetrate through these cracks and sprout out of the oxide layers. In contrast, compact oxide layers without any cracks are observed on the RE intermetallics after 


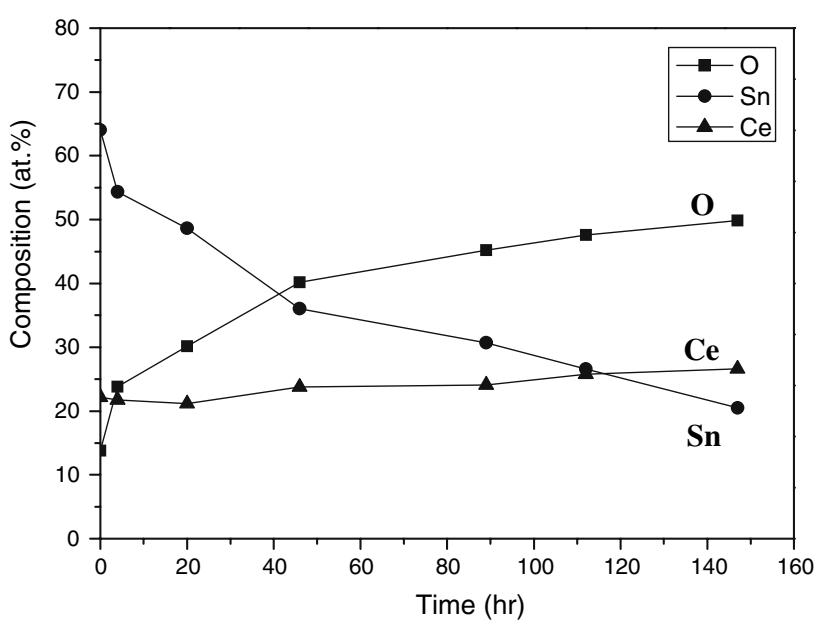

(a)

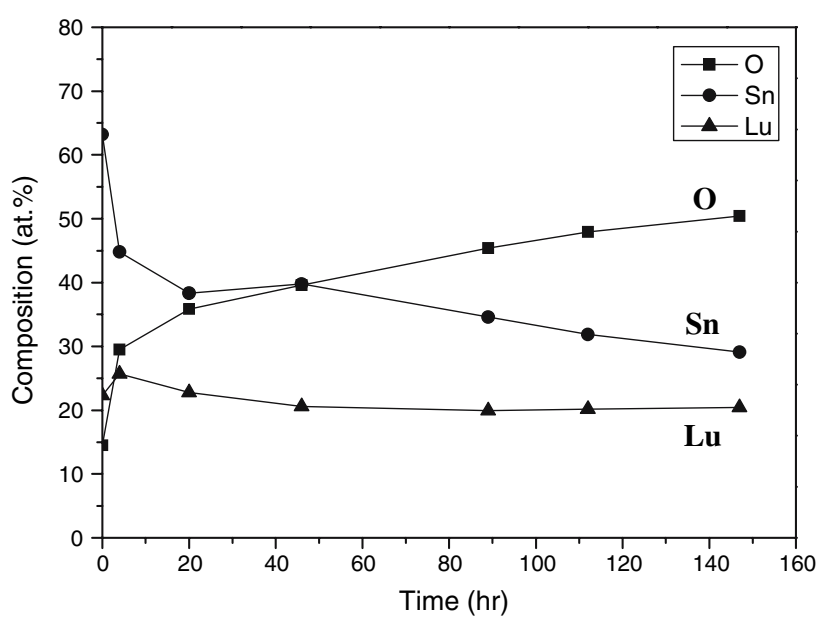

(b)

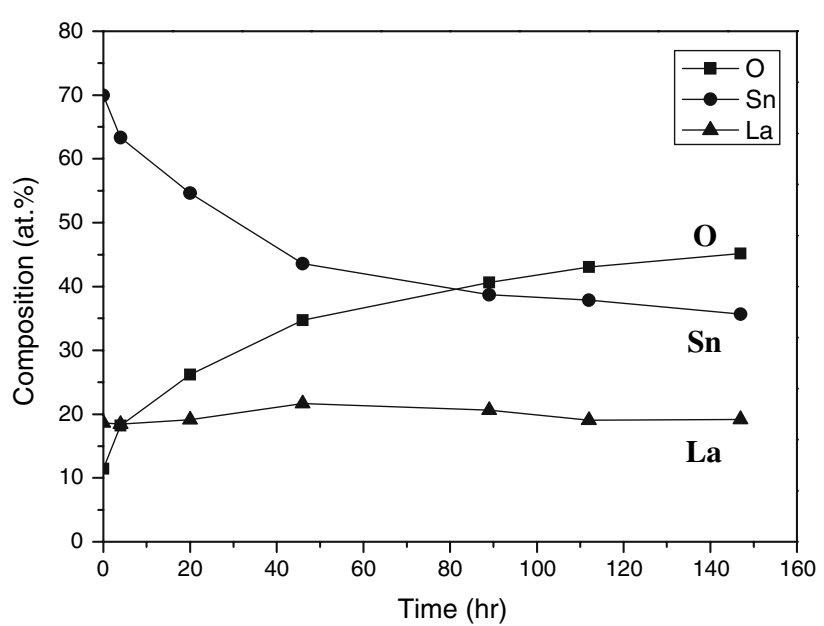

(c)

Fig. 8-Composition profiles of the outer surface of RE-containing intermetallic phases in Sn-6.6RE alloys during air storage at room temperature for various times: $(a) \mathrm{Sn}-6.6 \mathrm{Ce},(b) \mathrm{Sn}-6.6 \mathrm{Lu}$, and $(c)$ Sn-6.6La.

$150{ }^{\circ} \mathrm{C}$ storage in an air furnace for 1 hour (Figure 11). The absence of cracks, which act as the channels to transport the tin atoms out of the oxide layers, explains

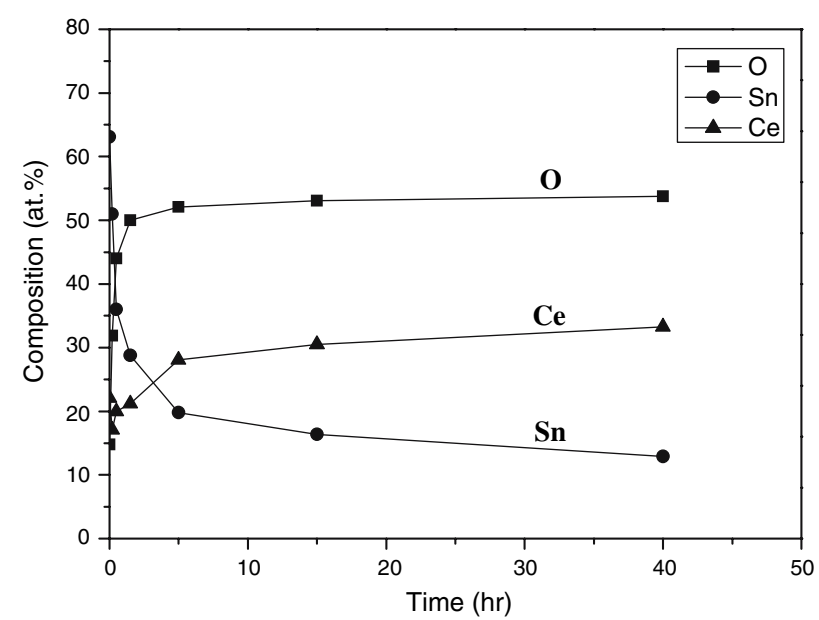

(a)

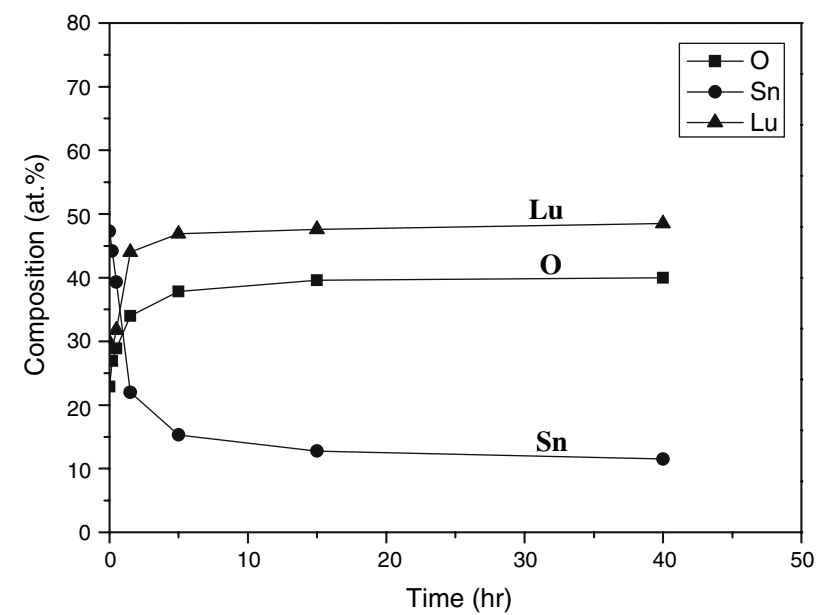

(b)

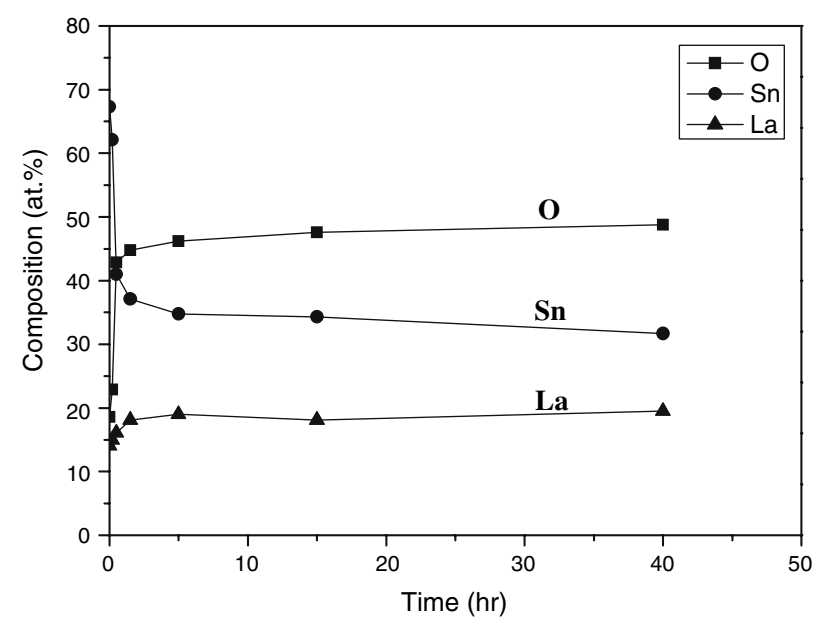

(c)

Fig. 9-Composition profiles of the outer surface of RE-containing intermetallic phases in Sn-6.6RE alloys stored at $150{ }^{\circ} \mathrm{C}$ in air furnace for various times: (a) Sn-6.6Ce, (b) Sn-6.6Lu, and (c) Sn-6.6La.

the scarce appearance of threadlike whiskers in the interior regions of the oxide layers on the RE intermetallics after $150{ }^{\circ} \mathrm{C}$ storage in an air furnace. Instead, the huge compressive stress resulted from the volume 

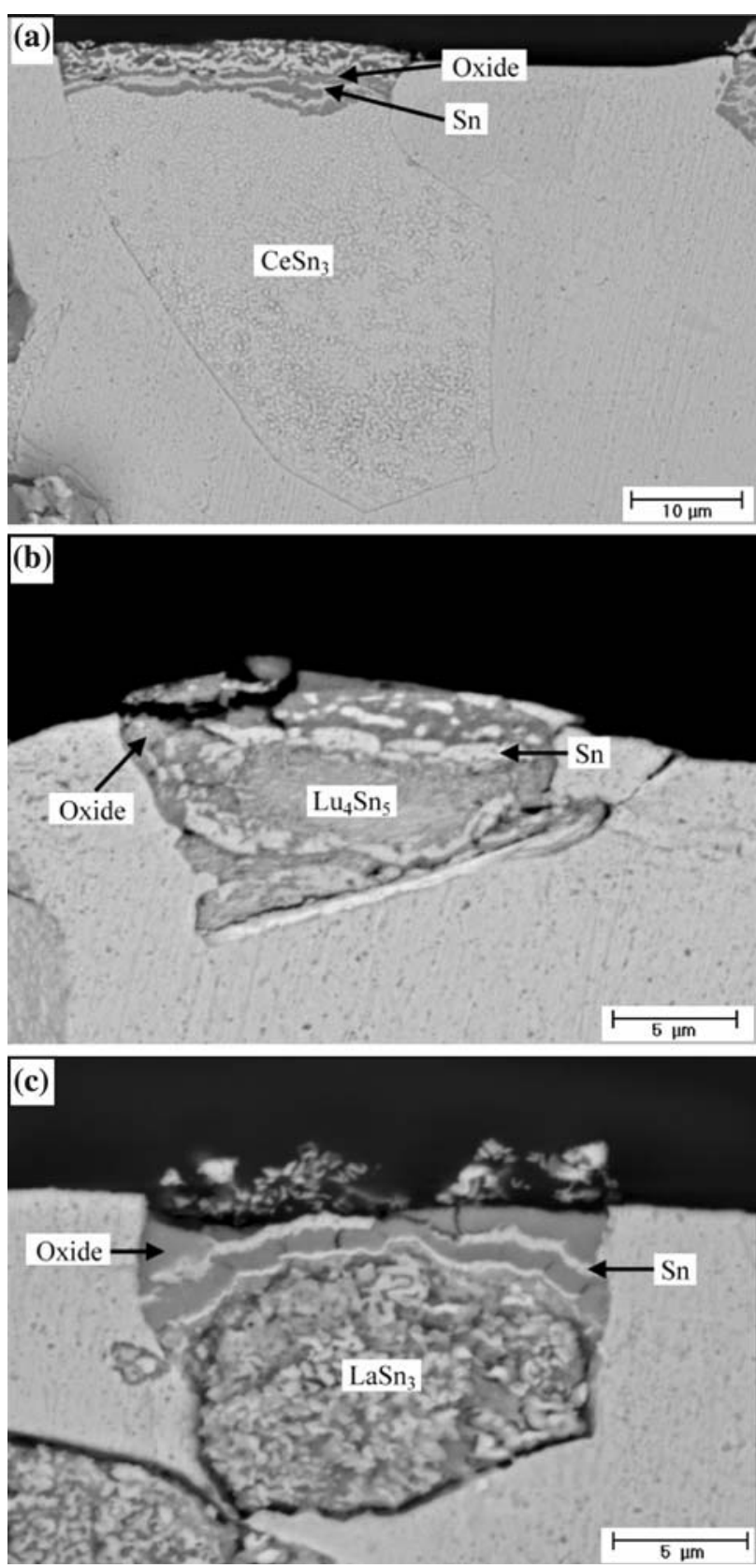

Fig. 10 - Cross sections of the oxidized RE-containing intermetallic phases in $\mathrm{Sn}-6.6 \mathrm{Re}$ alloys after air storage at room temperature for 48 h: (a) Sn-6.6Ce, (b) Sn-6.6Lu, and (c) Sn-6.6La.

expansion of the compact oxide layers leads to the formation of coarse hillocks around the RE intermetallic clusters. The main source of tin atoms in these coarse hillocks should be the matrix of Sn-6.6RE alloys near the RE intermetallics, although the released tin atoms from the oxidation of RE intermetallics also contribute to the hillock growth.

From the preceding mechanism, it appears that the slow growth of whiskers and hillocks for Sn-6.6La alloy in this study might have been related to its lower oxidation rate during storage in air. It is evidenced in Figure 12 that the TGA curve of the weight gain percentage for the Sn-6.6La specimen during air storage
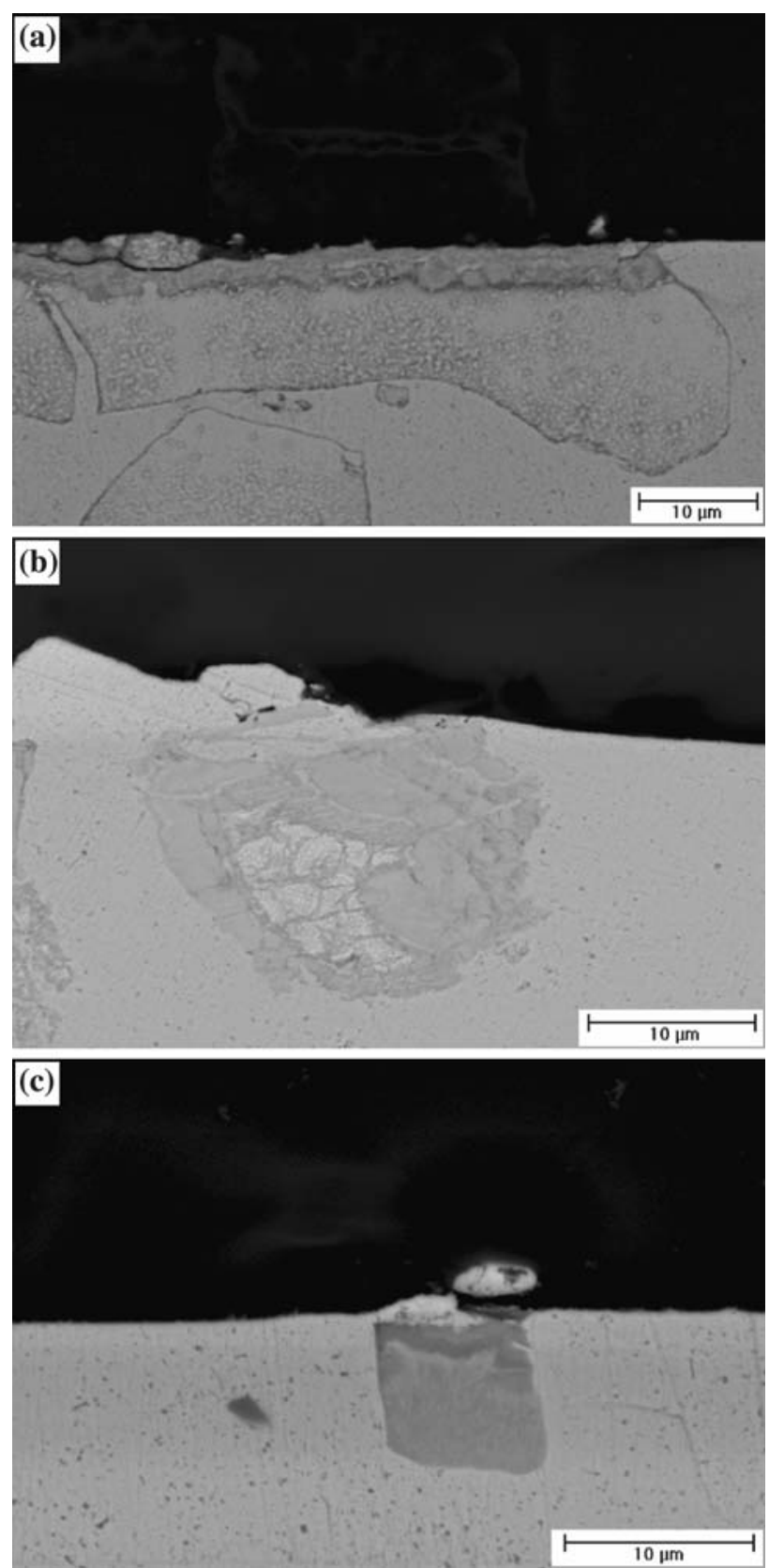

Fig. 11-Cross sections of the oxidized RE-containing intermetallic phases in $\mathrm{Sn}-6.6 \mathrm{Re}$ alloys stored at $150{ }^{\circ} \mathrm{C}$ in air furnace for $1.5 \mathrm{~h}$ : (a) Sn-6.6Ce, (b) Sn-6.6Lu, and (c) Sn-6.6La.

at $150{ }^{\circ} \mathrm{C}$ is much lower than those for the Sn-6.6Ce and Sn-6.6Lu specimens. A similar tendency can be seen in Figure 13, which presents the intermittent measurement of weight gain percentages of all Sn-6.6RE specimens stored at room temperature. Although the peritectic phase in Sn-6.6La alloy possesses an average size much finer than those in $\mathrm{Sn}-6.6 \mathrm{Ce}$ and $\mathrm{Sn}-6.6 \mathrm{Lu}$, they are distributed relatively close together in comparison to those in the other two alloys, as shown in Figure 1. Image analyses indicate that the area ratio of REcontaining peritectic phases in the Sn-6.6Ce, Sn-6.6Lu, and Sn-6.6La matrices are 10.54, 9.42, and 9.16 pct, respectively. It is evidenced that the total exposed area 


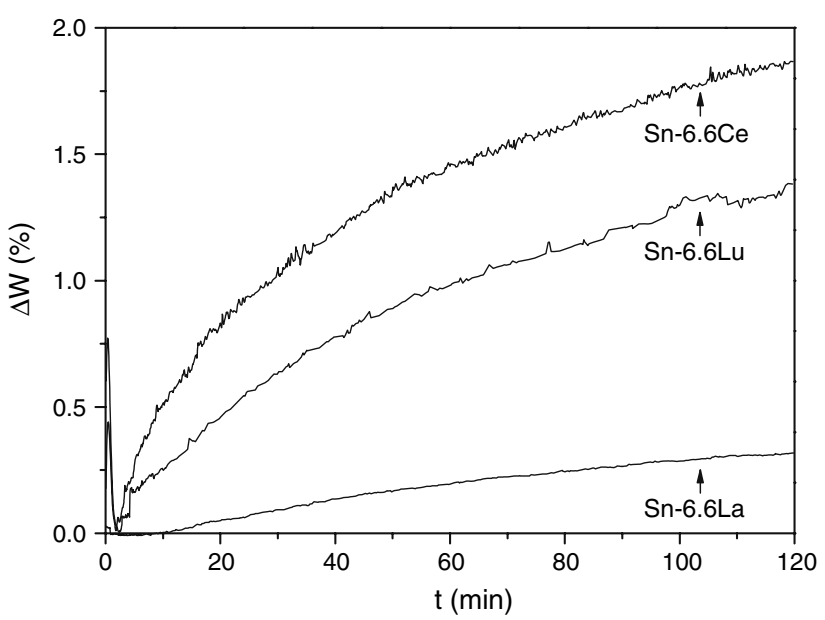

Fig. 12-Weight gain percentage $(\Delta W)$ of Sn-6.6Ce, Sn-6.6La, and $\mathrm{Sn}-6.6 \mathrm{Lu}$ alloys during thermal gravity analyses at $150{ }^{\circ} \mathrm{C}$ vs the oxidation time $(t)$.

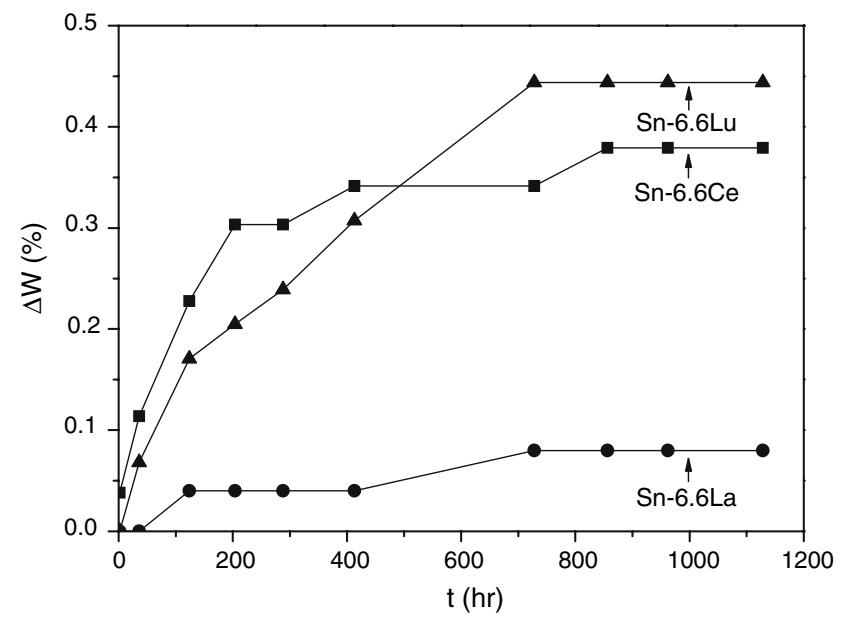

Fig. 13-Weight gain percentage $(\Delta W)$ of Sn-6.6Ce, Sn-6.6La, and $\mathrm{Sn}-6.6 \mathrm{Lu}$ alloys during air storage at room temperature for various time periods $(t)$.

of fine $\mathrm{LaSn}_{3}$ phase in $\mathrm{Sn}-6.6 \mathrm{La}$ alloy is near those of coarse $\mathrm{CeSn}_{3}$ and $\mathrm{Lu}_{4} \mathrm{Sn}_{5}$ in $\mathrm{Sn}-6.6 \mathrm{Ce}$ and $\mathrm{Sn}-6.6 \mathrm{Lu}$, respectively. The preceding results suggest that the $\mathrm{LaSn}_{3}$ phase in $\mathrm{Sn}-6.6 \mathrm{La}$ solder oxidized much more slowly than the $\mathrm{CeSn}_{3}$ and $\mathrm{Lu}_{4} \mathrm{Sn}_{5}$ in Sn-6.6Ce and $\mathrm{Sn}$ 6.6Lu, respectively. This leads to the conclusion that the higher chemical activity of $\mathrm{La}$ as compared to $\mathrm{Ce}$ and $\mathrm{Lu}$ causes the $\mathrm{LaSn}_{3}$ intermetallics to become more stable and, thus, exhibit a lower oxidation tendency than $\mathrm{CeSn}_{3}$ and $\mathrm{Lu}_{4} \mathrm{Sn}_{5}$. Another contributor to the slower whiskers and hillocks growth in $\mathrm{Sn}-6.6 \mathrm{La}$ alloy as compared to those in Sn-6.6Ce and Sn-6.6Lu might be the lower amount of pure tin released from the $\mathrm{LaSn}_{3}$ phase and the lower compressive stress that accumulated in the $\mathrm{LaO}$ oxide during air storage as a result of the small size of the $\mathrm{LaSn}_{3}$ peritectic phase.

The lower oxidation rate of $\mathrm{LaSn}_{3}$ intermetallics in comparison to $\mathrm{CeSn}_{3}$ and $\mathrm{Lu}_{4} \mathrm{Sn}_{5}$ also results in the absence of tin sprouts in its interior region during the initial storage at $150{ }^{\circ} \mathrm{C}$, as shown in Figure 4(c). In this case, the oxygen atoms tended to invade the interface between the $\mathrm{LaSn}_{3}$ phase and alloy matrix, which resulted in the earlier appearance of coarse hillocks around the $\mathrm{LaSn}_{3}$ in $\mathrm{Sn}-6.6 \mathrm{La}$ alloy as compared to those in Sn-6.6Ce and Sn-6.6Lu. However, the compressive stress resulted from the volume expansion of the oxidized $\mathrm{LaSn}_{3}$ phase being exhausted rapidly due to their small size. The growth of the coarse hillocks around $\mathrm{LaSn}_{3}$ ceased after $150{ }^{\circ} \mathrm{C}$ storage for a short duration. In the latter alloys, oxygen atoms react rapidly with $\mathrm{CeSn}_{3}$ and $\mathrm{Lu}_{4} \mathrm{Sn}_{5}$ intermetallic phases, and the tin atoms released are directly extruded out of the oxide layer to become the tin sprouts in the interior region of oxidized RE intermetallics after $150{ }^{\circ} \mathrm{C}$ storage for a short time. It is thus logical that Figures 4(a) and (b) reveal no coarse hillocks in Sn-6.6Ce and Sn-6.6Lu after storage at such an initial stage. However, increasing the storage time at $150{ }^{\circ} \mathrm{C}$ causes a drastic rise in compressive stress around the RE intermetallic clusters, which in turn causes the hillocks in $\mathrm{Sn}-6.6 \mathrm{Ce}$ and $\mathrm{Sn}-6.6 \mathrm{Lu}$ alloys to grow rapidly to large sizes.

\section{CONCLUSIONS}

The peritectic $\mathrm{LaSn}_{3}$ intermetallics formed in Sn-6.6La alloy during solidification process are much smaller than the $\mathrm{CeSn}_{3}$ and $\mathrm{Lu}_{4} \mathrm{Sn}_{5}$ phases in Sn-6.6Ce and $\mathrm{Sn}-6.6 \mathrm{Lu}$, respectively. The addition of various $\mathrm{RE}$ elements also leads to differences in the behavior of whisker and hillock growth in these Sn-6.6RE alloys. The discrepancy is not only attributed to the size of the RE-containing intermetallics but is also correlated with their oxidation tendencies. The lower oxidation rate of $\mathrm{LaSn}_{3}$ intermetallics, in contrast to those of $\mathrm{CeSn}_{3}$ and $\mathrm{Lu}_{4} \mathrm{Sn}_{5}$, results in the slower growth of threadlike whiskers in Sn-6.6La as compared to $\mathrm{Sn}-6.6 \mathrm{Ce}$ and $\mathrm{Sn}-6.6 \mathrm{Lu}$ alloys during air storage at room temperature. The early initiation of coarse hillocks in the Sn-6.6La specimen stored at $150{ }^{\circ} \mathrm{C}$ can also be understood under the consideration of its oxidation behavior. On the other hand, the coarse hillocks in Sn-6.6La alloy cease to grow after short-term storage at $150{ }^{\circ} \mathrm{C}$ due to the small size of the $\mathrm{LaSn}_{3}$ phase.

\section{ACKNOWLEDGMENTS}

This work was sponsored by the National Science Council, Taiwan, under Grant No. NSC 95-2221E002-160, and by the National Taiwan University, under Grant No. 95-R210.

\section{REFERENCES}

1. C.M.L. Wu, D.Q. Yu, C.M.T. Law, and L. Wang: J. Mater. Res., 2002, vol. 17 (12), pp. 3146-54.

2. C.M.L. Wu, D.Q. Yu, C.M.T. Law, and L. Wang: J. Electron. Mater., 2002, vol. 31 (9), pp. 928-32. 
3. Z.G. Chen, Y.W. Shi, Z.D. Xia, and Y.F. Yan: J. Electron. Mater., 2002, vol. 31 (10), pp. 1122-28.

4. M.A. Dudek, R.S. Sidhu, and N. Chawla: JOM, 2006, vol. 58 (6), pp. $57-62$.

5. T.H. Chuang and S.F. Yen: J. Electron. Mater., 2006, vol. 35 (8), pp. 1621-27.

6. T.H. Chuang: Scripta Mater., 2006, vol. 55 (11), pp. 983-86.
7. T.H. Chuang: Metall. Mater. Trans. A, 2007, vol. 38A, pp. 1048-55.

8. N. Vo, M. Kwoka, and P. Bush: IEEE Trans. Electron. Packag. Manufact., 2005, vol. 28 (1), pp. 3-9.

9. Constitution of Binary Alloys, M. Hansen and K. Anderko, eds., McGraw-Hill, New York, NY, 1958, pp. 461-62.

10. Constitution of Binary Alloys, M. Hansen and K. Anderko, eds., McGraw-Hill, New York, NY, 1958, pp. 891-92. 